\title{
Aggressive angiomyxoma of broad ligament: an uncommon mesenchymal tumor
}

\author{
Sunil Vitthalrao Jagtap ${ }^{1 *}$, Nitesh Narse ${ }^{1}$, Nitin S. Kshirsagar ${ }^{2}$, Shubham S. Jagtap $^{3}$
}

\author{
${ }^{1}$ Department of Pathology, ${ }^{2}$ Department of Obstetrics and Gynecology, Krishna Institute of Medical Sciences, Deemed \\ University, Karad, Maharashtra, India \\ ${ }^{3}$ Student, Governmennt Medical College, VMMC, Solapur, Maharashtra, India
}

Received: 23 April 2019

Revised: 23 May 2019

Accepted: 01 June 2019

\section{*Correspondence:}

Dr. Sunil Vitthalrao Jagtap,

E-mail: drsvjagtap@gamil.com

Copyright: (c) the author(s), publisher and licensee Medip Academy. This is an open-access article distributed under the terms of the Creative Commons Attribution Non-Commercial License, which permits unrestricted non-commercial use, distribution, and reproduction in any medium, provided the original work is properly cited.

\begin{abstract}
Aggressive angiomyxoma is a rare mesenchymal tumor occurring predominantly in the pelviperineal region. Authors present a case of a 70 years female presented with history of distention of lower abdomen with recurrent pain since 6 months. On clinical examination there was suspicion of fibroid. On USG it was reported as huge fleshy, soft tissue mass measuring 20x10x9 $\mathrm{cm}$ in lower abdominal flanks and pelvis with vascular pedicle attached to right parametrium. Pan-hysterectomy was performed. Right broad ligament showed mass measuring $18.5 \times 10 \times 6 \mathrm{~cm}$. On histopathological examination it was diagnosed as a case of Aggressive angiomyxoma of broad ligament. We are presenting this case for its extreme rarity, clinicohisto-pathological and radiological findings..
\end{abstract}

Keywords: Angiomyxoma, Histopathology, Hysterectomy, Tumor of broad ligament

\section{INTRODUCTION}

Aggressive angiomyxoma is a rare locally aggressive tumor of mesenchymal origin that occurs predominantly in females of reproductive age. ${ }^{1}$ Approximately 160 cases of aggressive angiomyxoma have been reported in the literature. $^{2}$

When it is located in female genital tract, clinically and on imaging it is considered. As a case of fibroid or ovarian neoplasm.

Histopathology plays a vital role in diagnosis and management of these cases. Author are presenting this case for its extreme rarity, clinicohisto pathological and radiological findings.

\section{CASE REPORT}

A 70 year female, postmenopausal since 20 years presented with history of distention of lower abdomen with recurrent pain since 6 months. There was other significant contributory history associated to this case. Systemic examinations were within normal limits except Per abdomen showing distention of lower abdomen. On per vaginal examination a large mass approximately measuring $15 \mathrm{~cm}$ was felt in right lateral region separated from uterus. On clinical examination it was suspected to be a case of fibroid uterus. On USG abdomen and pelvis showed huge mass measuring 20x10x9 cm, fleshy, compressing the soft tissue in lower abdomen-pelvic area. The mass was lamellated appearance. It has vascular pedicle which was attached to right parametrium. The 
uterus was anteverted, atrophic with normal shape echogenicity. Both the ovaries were atrophic with normal shape echogenicity. Mild ascites was noted. No significant lymphadenopathy was detected. Rest all organs were normal. MRI pelvis plain and contrast revealed right parametrial mass lesion with myxoid degenerative changes.

\section{Gross description}

Author received a pan-hysterectomy specimen. Uterus with cervix measured $8.5 \times 3 \times 1.7 \mathrm{~cm}$ and weighed $850 \mathrm{gm}$. At anterolateral wall of uterus on right sided broad ligament showed a thick fibrous band attached to it, which showed a single, huge, soft to firm, globular, grey white mass measuring 18.5x10x6 cm (Figure 1).

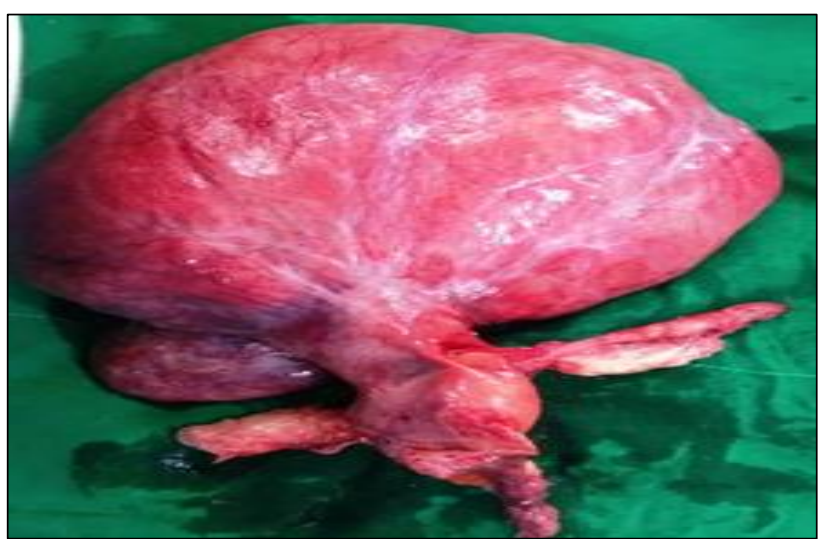

Figure 1: Single, huge, soft to firm, globular, grey white mass measuring $18.5 \times 10 \times 6 \mathrm{~cm}$ attached to broad ligament.

External surface showed congested blood vessels. Cut section was grey white, soft and showed extensive myxoid areas. External surface of cervix was unremarkable. On cut section endometrial canal measured $4.5 \mathrm{~cm}$ in length. Endometrial cavity showed a polyp measuring $1 \times 1 \times 0.2 \mathrm{~cm}$. Average endometrial thickness was $2 \mathrm{~mm}$. Wall of uterus was unremarkable. Average myometrial thickness was $0.6 \mathrm{~cm}$. The cervical canal measured $2.5 \mathrm{~cm}$ in length. The Right ovary measured $2.5 \times 1.7 \times 0.3 \mathrm{~cm}$ and the cut section was unremarkable. The Right fallopian tube was $6.5 \mathrm{~cm}$ long and the cut section was unremarkable. The Left ovary measured $2.3 \times 1.7 \times 0.5 \mathrm{~cm}$ and the cut section was unremarkable. The Left fallopian tube was $5 \mathrm{~cm}$ long and the cut section was unremarkable.

\section{Microscopic description}

Multiple sections from broad ligament mass showed tumor composed of stellate and spindle shaped mesenchymal cells embedded in a loose myxoid stroma, along with small to medium sized blood vessels within the tumor (Figure 2). In areas vessels are dilated. Loose hypocellular areas with collagen tissue is noted on high power view (Figure 3). There is no evidence of atypia or necrosis. No mitotic activity is noted. The complete histopathological diagnosis given was AngiomyxomaMass arising from right sided broad ligament , along with Chronic non-specific cervicitis, Cystic atrophy Endometrium. Functional endometrial polyp, Unremarkable Bilateral ovaries and fallopian tubes.

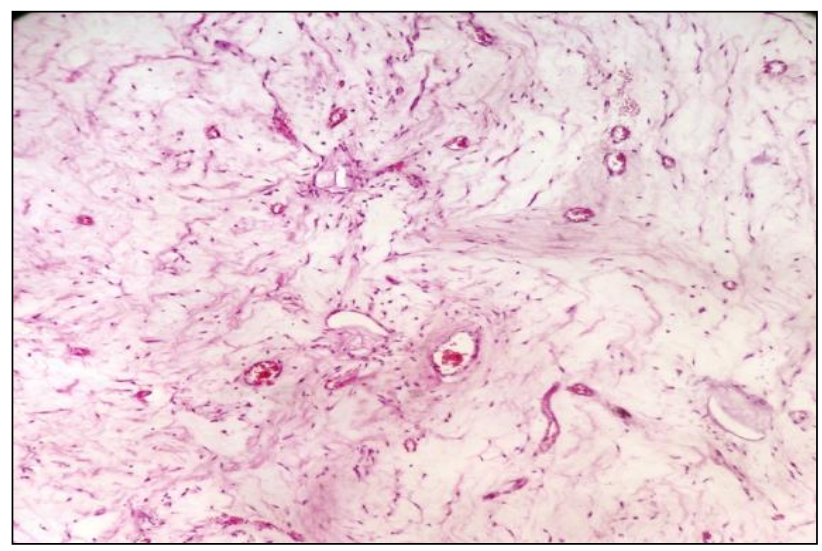

Figure 2: Broad ligament tumor composed of stellate and spindle shaped mesenchymal cells, loose myxoid stroma, along with small to medium sized blood vessels (H and $\mathrm{E}$ stain, 40x).

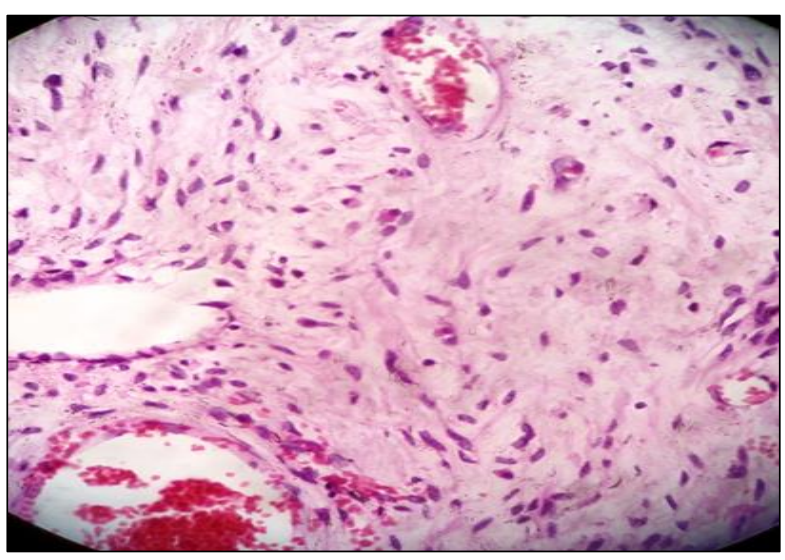

Figure 3: Tumor composed of stellate and spindle shaped mesenchymal cells, loose myxoid stroma, along with small to medium sized blood vessels.(H and E stain, 100x).

\section{DISCUSSION}

Aggressive angiomyxoma is a rare mesenchymal tumor composed of divergent differentiation of fibroblastic, myofibroblastic and smooth muscle cell origin on ultrastructural analysis. It is commonly noted in female genital tract, vulva, vagina, cervix, parametrium. ${ }^{3}$ In 1983 Steepar and Rosai described case of Aggressive angiomyxoma of female pelvis and perineurum. ${ }^{4}$ It is of two types on clinical presentation as subcutaneous angiomyxoma and deep seated angiomyxoma. In authors case it is reported in broad ligament which is extremely rare in location and a literature search showed very few cases at this site. Deep angiomyxoma occurs in all age 
group with predominant 3 to 5 th decade. ${ }^{3}$ On clinical presentation usually present as fullness in lower abdominal, abdominal distension and pain. In authors case clinically and radiologically suspected of uterine fibroid. On histopathology showed huge mass attached to broad ligament with thick cord like fibrous band with feeding blood vessels. It was measuring $18.5 \times 10 \times 6 \mathrm{~cm}$. Usually aggressive angiomyxomas are large masses and involves deep tissue at the time of diagnosis. ${ }^{3}$

On microscopic examination shows a hypocellular mesenchymal tumor composed of myxomatous component with elongated, bland, slender spindle shaped cells having mild atypia. These are scattered stellate cells and numerous proliferating thin to thick walled blood vessels. Focal areas of congestion and mild mononuclear cell infiltration are evident. There are usually no areas of necrosis and mitotic activity. These tumors are rapidly growing, shows minimal or no infiltration in surrounding tissue and tendency to reoccur after local excision from initial resection recurrence may be within 9-180 months. ${ }^{5,6}$ The differential diagnosis are myxoma, low grade liposarcoma, myxofibrosarcoma, angiomyxofibroma, fibroepithelial stromal polyp, myxoid neurofibroma etc. ${ }^{7,8}$ Angiomyxomas are usually $<5 \mathrm{~cm}$ with well circumscribed lesions and have rounded or epithelial cell clusters with alternating hypercellular areas. While aggressive angiomyxomas are larger $>5 \mathrm{~cm}$, not circumscribed and hypocellular with spindle or stellate cells with infiltrating margins. Myxofibrosarcoma shows cytological atypia and frequent mitotic figures. The myxoid neurofibroma are positive for S-100, while aggressive angiomyxoma are negative. The superficial angiomyxoma are smaller, located subcutaneously but lack thick wall blood vessels and usually are ER, PR negative. Myxofibrosarcoma shows spindle cells with atypia, increased mitosis. The stroma is myxomatous with curvilinear blood vessels. Most of them are located in extremities. ${ }^{8}$ Immunohistochemical study for vimentin, S-100, Desmin, CD34, ER, PR, SMA etc. have been studied. ${ }^{9}$ As tumor has a divergent differentiation there is no specific tumor marker. Aggressive angiomyxoma are usually diffusely positive for desmin and few cases having ER, PR positive have been noted. These cases are treated with local wide excision. The rate of recurrence is high and reported incidence is $30-70 \%$ of the cases. ${ }^{10}$ As there is high risk for recurrence, there is a need to keep close follow-up of these cases.

\section{CONCLUSION}

Author are reporting extremely rare case of aggressive angiomyxoma of broad ligament for its clinical radiological and histopathological findings. Aggressive angiomyxoma can mimic many clinical and histological entities. As it is a rare case it may be interpreted as fibroid or ovarian neoplasm, so it's important to be aware of this entity.

\section{Funding: No funding sources Conflict of interest: None declared \\ Ethical approval: Not required}

\section{REFERENCES}

1. Surabhi VR, Garg N, Furmovitz M, Bhosale P, Prasad SR, Meis JM. Aggressive angiomyxomas : a comprehensive imaging review with clinical and histopathologic correlation. Am J Roentgenol. 2014;202(6):1171-8.

2. Tsarpalis DC, Giannakopoulos CK, Lagadas AA, Toufexi EG. Aggressive angiomyxoma: case report and review of the literature .Eur J Gynaecol Oncol. 2007;28(6):480-2.

3. Fetsch JF, Laskin WB, Lefkowitz M, Kindblom LG, Meis-Kindblom JM. Deep angiomyxoma: a clinicopathologic study of 29 female patients. Cancer. 1996;78(1):79-90.

4. Steeper TA, Rosai J. Aggressive angiomyxoma of the female pelvis and perineum. Report of nine cases of a distinctive type of gynecologic soft-tissue neoplasm. Am J Surg Pathol. 1983;7(5):463-75.

5. Behrnwala KA, Thomas JM. Aggressive angiomyxoma: A distinct clinical entity. Eur J Surg Oncol. 2003;29(7):559-63.

6. Begin LR, Clement PB, Kirk ME, Jothy S, McCaughey WT, Ferenczy A. Aggressive angiomyxoma of pelvic soft parts: A clinicopathologic study of nine cases. Hum Pathol. 1985;16(6):621-8.

7. Stephenson BM, Williams EV. Aggressive angiomyxoma of the female perineum and pelvis. $\mathrm{Br}$ J Surg. 1992;79(11):1181.

8. Jagtap SV, Jain A, Jagtap SS, Kshirsagar AY. Highgrade myxofibrosarcoma-presented as a large mass of right upper arm. Indian J Pathol Microbiol. 2015;58(1):105-7.

9. Van Roggen JF, van Unnik JA, Briaire-de Bruijn IH, Hogendoorn PC. Aggressive angiomyxoma: a clinicopathological and immunohistochemical study of 11 cases with long-term follow-up. Virchows Arch. 2005;446(2):157-63.

10. Chan YM, Hon E, Ngai SW, Ng TY, Wong LC. Aggressive angiomyxoma in females: is radical resection the only option? Acta Obstet Gynecol Scand. 2000;79(5):432.

Cite this article as: Jagtap SV, Narse N, Kshirsagar NS, Jagtap SS. Aggressive angiomyxoma of broad ligament - an uncommon mesenchymal tumor. Int $\mathbf{J}$ Reprod Contracept Obstet Gynecol 2019;8:2913-5. 